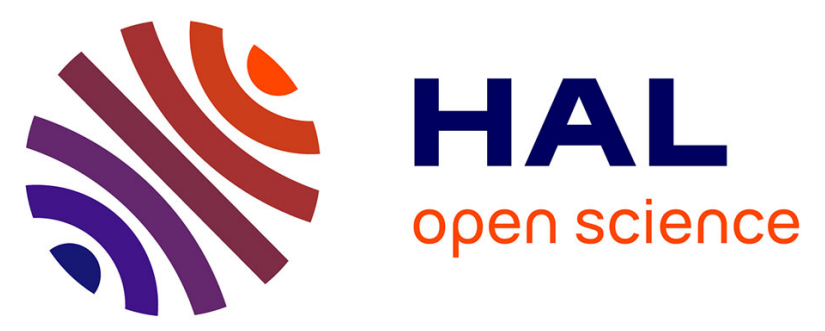

\title{
Excess mortality associated with the 2009 A(H1N1)v influenza pandemic in Antananarivo, Madagascar.
}

S. Rajatonirina, B. Rakotosolofo, F. Rakotomanana, L. Randrianasolo, M. Ratsitoharina, H. Raharinandrasana, Jean-Michel Heraud, V. Richard

\section{- To cite this version:}

S. Rajatonirina, B. Rakotosolofo, F. Rakotomanana, L. Randrianasolo, M. Ratsitoharina, et al.. Excess mortality associated with the 2009 A(H1N1)v influenza pandemic in Antananarivo, Madagascar.. Epidemiology and Infection, 2012, pp.1-6. 10.1017/S0950268812001215 . pasteur-00719969

\section{HAL Id: pasteur-00719969 \\ https://hal-riip.archives-ouvertes.fr/pasteur-00719969}

Submitted on 24 Jul 2013

HAL is a multi-disciplinary open access archive for the deposit and dissemination of scientific research documents, whether they are published or not. The documents may come from teaching and research institutions in France or abroad, or from public or private research centers.
L'archive ouverte pluridisciplinaire HAL, est destinée au dépôt et à la diffusion de documents scientifiques de niveau recherche, publiés ou non, émanant des établissements d'enseignement et de recherche français ou étrangers, des laboratoires publics ou privés. 


\title{
Excess mortality associated with the 2009 A(H1N1)v influenza pandemic in Antananarivo, Madagascar
}

\author{
S. RAJATONIRINA ${ }^{1}$, B. RAKOTOSOLOFO ${ }^{2}$, F. RAKOTOMANANA ${ }^{1}$, \\ L. RANDRIANASOLO ${ }^{1}$, M. RATSITOHARINA ${ }^{1}$, H. RAHARINANDRASANA ${ }^{2}$, \\ J.-M. HERAUD ${ }^{3}$ AND V. RICHARD ${ }^{1 *}$ \\ ${ }^{1}$ Epidemiological Unit, Institut Pasteur de Madagascar, Antananarivo, Madagascar \\ ${ }^{2}$ Bureau Municipal d'Hygiène, Antananarivo, Madagascar \\ ${ }^{3}$ National Influenza Centre, Virology Unit, Institut Pasteur de Madagascar, Antananarivo, Madagascar
}

Received 22 June 2011; Final revision 12 May 2012; Accepted 23 May 2012

\section{SUMMARY}

It is difficult to assess the mortality burden of influenza epidemics in tropical countries. Until recently, the burden of influenza was believed to be negligible in Africa. We assessed the impact of the 2009 influenza epidemic on mortality in Madagascar by conducting Poisson regression analysis on mortality data from the deaths registry, after the first wave of the 2009 A(H1N1) virus pandemic. There were $20 \%$ more human deaths than expected in Antananarivo, Madagascar in November 2009, with excess mortality in the $\geqslant 50$ years age group (relative risk 1.41). Furthermore, the number of deaths from pulmonary disease was significantly higher than the number of deaths from other causes during this pandemic period. These results suggest that the $\mathrm{A}(\mathrm{H} 1 \mathrm{~N} 1) 2009$ virus pandemic may have been accompanied by an increase in mortality.

Key words: A(H1N1) virus, Madagascar, mortality, pandemic.

\section{INTRODUCTION}

Influenza has a considerable morbidity and mortality burden, causing an estimated one million deaths per annum, worldwide [1]. However, the number of deaths is probably greater during pandemics $[2,3]$, such as those caused by the pandemic A(H1N1) 2009 virus, which emerged in Mexico in March 2009 [4].

It is difficult to estimate the burden of influenza in terms of the number of deaths, even in temperate countries, and this task is even more challenging in developing countries [2]. Influenza infection is not confined to well-defined periods and is rarely

\footnotetext{
* Author for correspondence: Dr V. Richard, Epidemiological Unit, Institut Pasteur de Madagascar, BP 1274, Antananarivo 101, Madagascar.

(Email: vrichard@pasteur.sn)
}

confirmed by laboratory testing $[5,6]$. Thus, until recently, the burden of influenza was believed to be negligible in Africa. Some countries, including Madagascar [7], have set up a sentinel surveillance network, to estimate trends and the burden of influenza. The occurrence of pandemic infections has made it possible to test these networks.

The first cases of pandemic A(H1N1) 2009 virus infection in Madagascar were confirmed in August 2009. All confirmed cases had a history of travel to an affected area. Transmission of pandemic $\mathrm{A}(\mathrm{H} 1 \mathrm{~N} 1)$ 2009 virus within the community began in October 2009, in the capital, Antananarivo. The sentinel surveillance system was used to monitor the spatial and temporal progression of the outbreak, but could not estimate its burden, as most cases of influenza were not confirmed by laboratory testing. Epidemic reports 
also lack numerical data from which the severity of a particular epidemic can be determined. We therefore investigated the impact of the recent pandemic $\mathrm{A}(\mathrm{H} 1 \mathrm{N1}) 2009$ virus infection on mortality among the inhabitants of Antananarivo.

\section{METHODS}

The study was performed in Antananarivo, the capital city of Madagascar, which is located in the central highlands. According to data from the civic authorities, the city had a population of about 1.5 million in 2004. Antananarivo consists of administrative, commercial, industrial and residential areas, with patches of agricultural land, mostly rice fields. The city is divided into six administrative districts.

Influenza surveillance in this city is based on data collected from sentinel general practitioners (SGPs) working at four primary healthcare centres. Each participating SGP reported the number of influenzalike illnesses (ILIs) meeting the case definition criteria and the total number of patient visits for each day of reporting. The ILI case definition criteria were fever and a cough or sore throat. SGPs were asked to communicate encrypted data via their mobile telephones (encrypted SMS), at least once daily, from Monday to Friday, notwithstanding occasional clinic closures programmed in routine weekday-weekend schedules. Virological and epidemiological surveillance was linked for identification and characterization of the influenza viruses circulating in Madagascar. Specimens were collected by members of the sentinel network. Suspected cases were tested for the various influenza viruses [B, seasonal $\mathrm{A}(\mathrm{H} 1 \mathrm{~N} 1)$ and $\mathrm{A}(\mathrm{H} 3 \mathrm{~N} 2)$, and pandemic $\mathrm{A}(\mathrm{H} 1 \mathrm{~N} 1) \mathrm{pdm} 09]$ with the CDC real-time RT-PCR protocol for the detection and characterization of human and swine influenza. This detection kit includes panels of oligonucleotide primers and double-labelled $\left(\right.$ Taqman ${ }^{\mathbb{R}}$ ) probes. We used the Ag-Path One-Step RT-PCR kit $(\mathrm{P} / \mathrm{N}$ : 4387391, Ambion, USA) for amplification.

We obtained death certificate data, for 2007 to 2009, from the three urban centres in Antananarivo at which all deaths are recorded in paper-based registers. In Antananarivo and its suburbs, a death certificate must be obtained before casketing of the body. Laboratory confirmation of influenza infection was obtained for a few cases of acute respiratory disease in hospital, but for none of the deaths. Furthermore, mortality data are not routinely analysed in Madagascar.
Each death certificate, including the deceased's date of birth, sex, date of death, address and the recorded cause of death, was classified according to the International Classification of Diseases (10th revision). Data were input into Access ${ }^{\circledR}$ (Microsoft, USA) and analysed with the R statistical package [8].

Mortality was assessed as the number of deaths per month or per year, for the total population or for a given age group. We defined six age groups $(<10$, $10-19,20-29,30-39,40-49, \geqslant 50$ ). Rates were calculated with an estimated population growth rate of $4.8 \%$, taking into account the natural rate of population growth for the whole of Madagascar $(2.8 \%$ according to the National Institute for Statistics, Madagascar) and population growth specific to Antananarivo due to the movement of individuals from rural areas to the city.

We analysed all deaths reported in 2009 and compared the actual number of deaths with the number expected based on the mean death rate for the two preceding years $(2007,2008)$. Mortality in the total population or in defined subpopulations, by calendar month and calendar year, were studied by regression analysis in which we assumed that deaths occurred independently and at random within populations, thereby following a Poisson distribution. A Poisson distribution is, by definition, the distribution of the number of events over a fixed time interval, provided that the events occur randomly and independently over time, and at a constant rate. This distribution may be seen as a limiting form of binomial distribution. Poisson regression analysis can be applied to count data and is based on the assumption that the event concerned is rare $[9,10]$.

\section{RESULTS}

From 1 January 2007 to 31 December 2009, 24516 deaths were reported. The median age at death was 48 years (interquartile range $22-66$ years). The $\geqslant 50$ years age group accounted for $46 \cdot 7 \%$ of all deaths. No statistical differences were found between age groups based on calendar years $(P=0 \cdot 16)$. None of the deaths recorded during these three years were declared as influenza-associated.

The sex ratio $(\mathrm{M} / \mathrm{F})$ was 1.24 and no significant difference in death rate was found between the sexes, on the basis of calendar year $(P=0 \cdot 3)$. We plotted the number of deaths per week in Antananarivo in 2009 against the numbers of deaths per week in 2007 and 


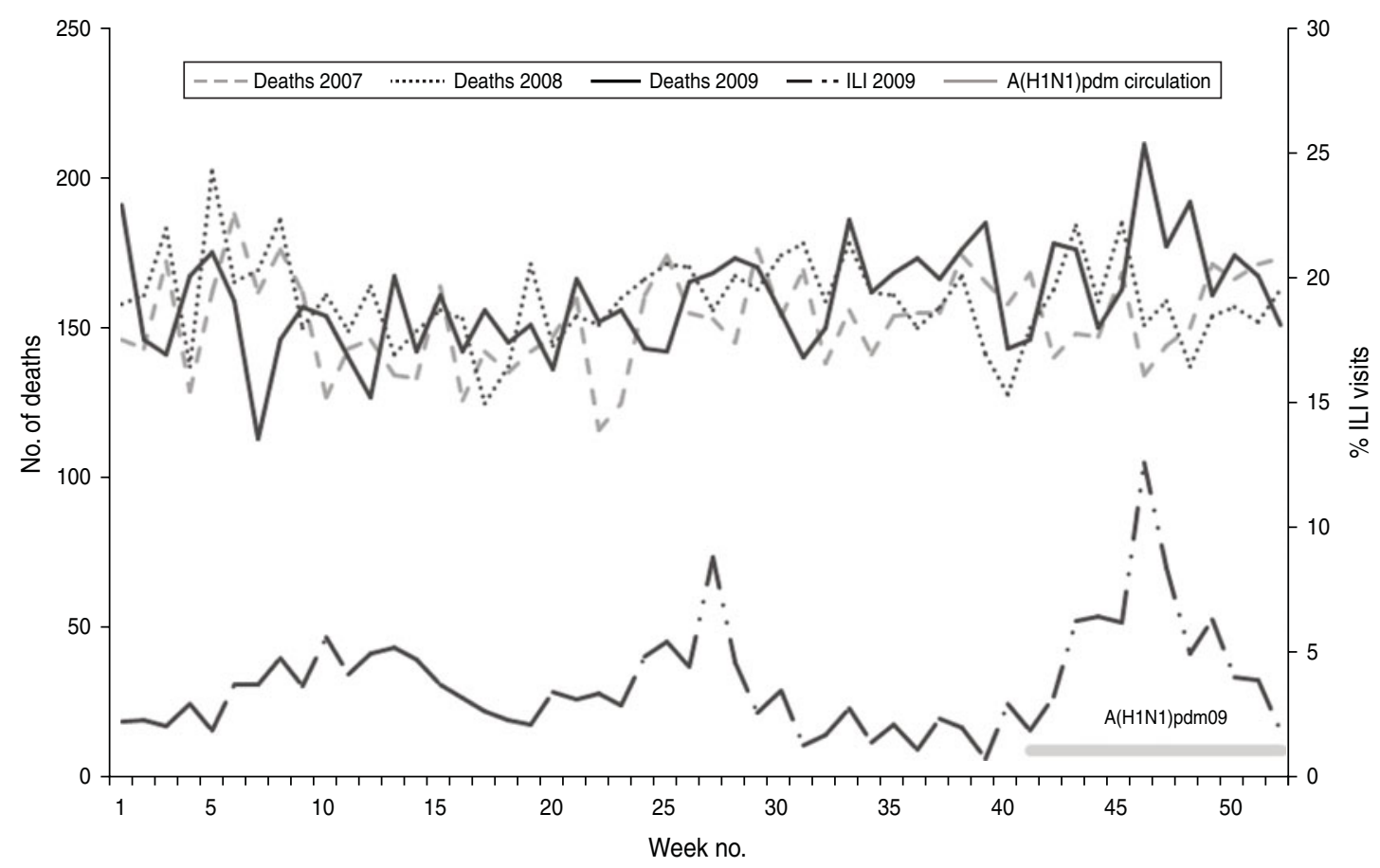

Fig. 1. Numbers of deaths per week registered from 2007 to 2009 and of influenza-like illness (ILI) reported, based on weekly visits, in 2009 in Antananarivo.

2008 (Fig. 1), and the ILI data collected by sentinel surveillance methods in 2009. Virological surveillance showed that the pandemic $\mathrm{A}(\mathrm{H} 1 \mathrm{~N} 1) 2009$ virus was circulating in the community in Antananarivo between weeks 42 and 53.

There were 7929 deaths [crude mortality rate (CMR) 6.8/1000)] reported in 2007, 8285 (CMR 6.8/ $1000)$ in 2008, and 8302 (CMR 6.5/1000) in 2009. The annual number of deaths observed was significantly lower in 2009 than expected $(n=8696)$ from the mean CMR for 2007 and 2008 [relative risk (RR) 0.95, $95 \%$ confidence interval (CI) 0.92-0.98]. Sentinel surveillance showed an increase in pandemic $\mathrm{A}(\mathrm{H} 1 \mathrm{~N} 1) 2009$ virus infection in the population in November 2009 (Fig. 1), with an epidemic peak occurring in week 47. A similar trend was observed for the number of deaths. The number of deaths observed $(n=784)$ in November 2009 was significantly larger (RR 1·11, 95\% CI 1·01-1·23) than expected $(n=699)$. No significant difference was found for any other month except February, for which there were fewer deaths reported in 2009 (RR 0.86, 95\% CI 0.82-0.90) due to underreporting as a result of the civil crisis in Madagascar [11].

By comparing the number of deaths occurring each week, we were able to identify weeks in which significantly more deaths occurred in 2009 than expected from the data for 2007-2008 $(P<0 \cdot 01)$ : week 46 (RR 1·42, 95\% CI 1·16-1·77), week 48 (RR 1·23, $95 \%$ CI $1 \cdot 01-1 \cdot 52)$.

Differences were also found for age group and year of death $(P<0 \cdot 01)$, with more deaths observed $[n=358$, mortality rate $2 \cdot 4 / 1000]$ than expected $(n=250$, mean mortality rate for November 2007-November 2008; 1.7/1000) in November 2009 for the $>50$ years age group (RR $1 \cdot 41,95 \%$ CI $1 \cdot 21-1 \cdot 68)$. No significant differences were found between 2008 and 2007 for week or age group (Fig. 2).

Statistically significant excess mortality was observed for the period during which pandemic A(H1N1) 2009 virus was circulating (Fig. 3).

We compared the causes of death during November between the three years (Table 1). The frequency of death from pneumonia and other pulmonary diseases was significantly higher $(17 \cdot 3 \%)$ in November 2009 than in the November of the previous years $(P=0 \cdot 04)$.

\section{DISCUSSION}

Despite a lower annual mortality rate for 2009 than for 2007-2008, due to the political crisis in Madagascar during the first quarter of 2009 and an underreporting of deaths in February 2009, our findings suggest 

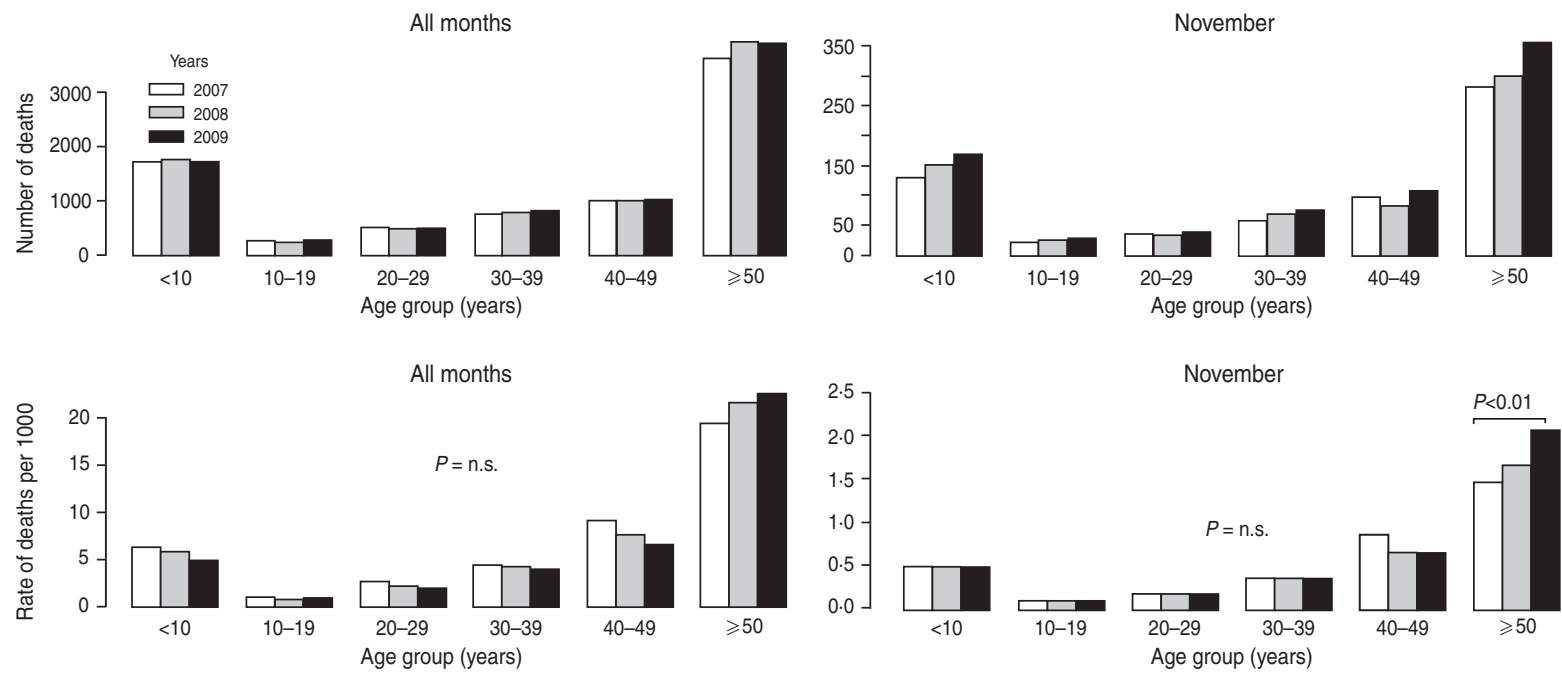

Fig. 2. Numbers of deaths and mortality rates by age group in Antananarivo in 2007-2009 and in November 2007-2009.

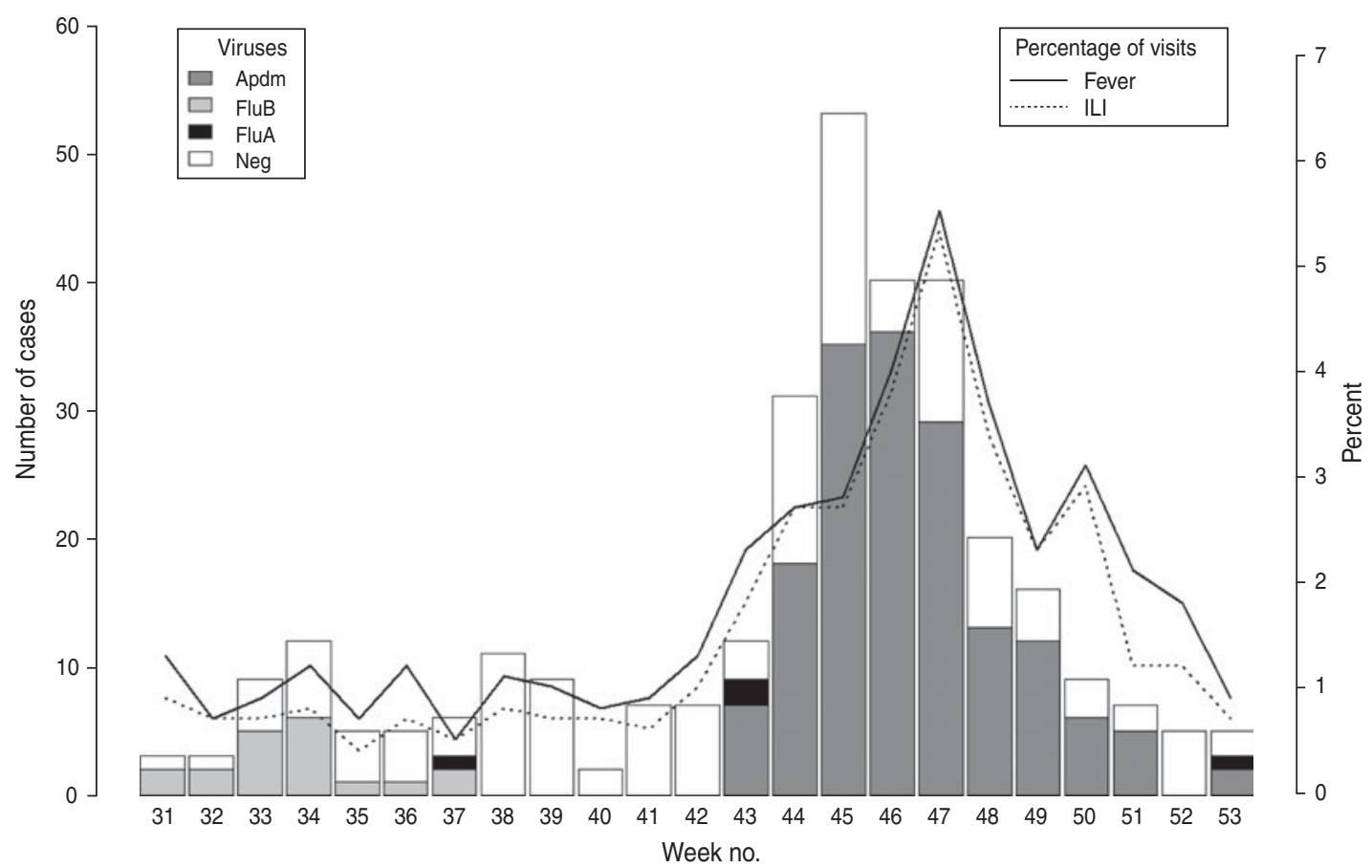

Fig. 3. Time-series distribution of fever syndromes, influenza-like illness (ILI) and confirmed cases of influenza in Antananarivo, Madagascar, 2009.

that mortality rates in adults aged $\geqslant 50$ years were significantly higher than expected in November 2009. This increase in mortality coincided with the circulation of the $\mathrm{A}(\mathrm{H} 1 \mathrm{~N} 1) \mathrm{v}$ influenza virus in the community during the 2009 pandemic. Most of the excess deaths in our study were not identified as influenzarelated deaths, because influenza infections were generally not confirmed virologically or specified on hospital discharge forms or death certificates, despite the systematic testing of cases with acute respiratory disease requiring hospital admission, including a substantial number of patients in primary and emergency care, during the pandemic period. Thus, studies focusing on the deaths of individuals with laboratoryconfirmed influenza $\mathrm{A}(\mathrm{H} 1 \mathrm{~N} 1) \mathrm{v}$ might not have picked up this increase in mortality. Many of these deaths probably occurred in the community, as is generally observed in Madagascar, because family incomes are low and the costs of hospitalization are high. 
Table 1. Mortality causes in November 2007, 2008 and 2009

\begin{tabular}{lrrr}
\hline \hline Causes of death & \multicolumn{1}{l}{2007} & \multicolumn{1}{l}{2008} & \multicolumn{1}{l}{2009} \\
\hline Pneumonia, other lung diseases & $87(13 \cdot 7)$ & $86(12 \cdot 9)$ & $136(17 \cdot 3)$ \\
Other underlying causes & $547(86 \cdot 3)$ & $578(87 \cdot 1)$ & $648(82 \cdot 7)$ \\
\hline \hline
\end{tabular}

Values given are $n(\%)$.

This increase in mortality during periods of viral circulation is consistent with the increase in mortality during this period being due to influenza virus. A high mortality rate was previously reported in 2002, during an outbreak of seasonal influenza $\mathrm{A}(\mathrm{H} 3 \mathrm{~N} 2)$. This outbreak occurred in the province of Fianarantsoa and mostly affected children aged $<5$ years and adults aged $>60$ years [12]. Another study of an influenza outbreak reported a mortality rate of $6 / 1000$ in the Democratic Republic of the Congo [13].

During seasonal epidemics of influenza, mortality rates are generally highest in the elderly population. Conversely, during pandemic influenza, mortality rates tend to be higher in younger age groups. This shift in mortality towards younger age groups is considered to be a signature feature of pandemics [14]. The shift in the age signature during the last wave of the influenza pandemic was highlighted by data for the USA and France, in which mortality rates were relatively high in young people (aged $<20$ years) infected with the 2009 pandemic influenza $\mathrm{A}(\mathrm{H} 1 \mathrm{~N} 1)$ virus [15]. We obtained different results. We found no difference in mortality between 2009 and the two previous years for young people. Instead, mortality rates were highest for older adults (aged $\geqslant 50$ years) in 2009, a pattern closer to that for seasonal influenza, in which the elderly are considered to be at the highest risk of complications and death [16].

The genetic similarity between the viruses responsible for the 1918 and 2009 pandemics is believed to have resulted in higher levels of protection in individuals who were alive during the emergence of the 1918 pandemic virus [16]. However, the higher mortality rates recorded for older adults in Madagascar suggests that levels of protection are low in the members of this age group in Madagascar.

The mortality burden of influenza remains largely undocumented in developing countries but it is undoubtedly great in Africa, owing to underlying tropical diseases, immunosuppression and malnutrition, which greatly complicate the infection $[17,18]$. Nonspecific factors related to poverty may have contributed, at least in part, to the excess mortality observed in Madagascar. Our findings are consistent with the notion that African populations may be at higher risk of death from pandemic influenza [17].

The method of analysis used in this study does not provide a complete picture of the impact of pandemic $\mathrm{A}(\mathrm{H} 1 \mathrm{~N} 1)$ influenza virus on mortality, because none of the deaths were confirmed by laboratory tests to be due to influenza infection. The actual number of influenza-related deaths is therefore unknown. However, the coincidence of the period of excess mortality with the period of virus circulation provides support for the hypothesis that these excess deaths were due to pandemic influenza. There may have been other factors affecting mortality rates during the reference periods in the previous 2 years, potentially attenuating the excess mortality detected in 2009. On the basis of these findings, we recommend the weekly collection of data concerning excess deaths due to influenza pneumonia. This information could then be used for the early recognition of influenza epidemics and assessments of the geographical location and relative magnitude of on the outbreak on a weekby-week basis [19].

This study has several limitations. During the pandemic period, the influenza laboratory activities focused on influenza viruses, largely ignoring other viruses, due to logistic constraints and a lack of human resources. This may have resulted in an underdiagnosis of other respiratory virus infections. Virological surveillance in 2008-2009 in Antananarivo [20] demonstrated a co-existence of influenza and other viruses in the population, with high rates of viral co-infection $(29 \cdot 4 \%)$. However, Chan et al. [21] found the rate of co-infection to be $<1.5 \%$ during the pandemic period. They also found that mortality rates were higher in patients infected with $\mathrm{A}(\mathrm{H} 1 \mathrm{N1}) \mathrm{pdm} 09$ than in patients infected with other respiratory viruses.

Some other biases must also be considered. The numbers of deaths attributed to respiratory causes may have been overestimated during this period, due to media coverage of this health problem. Finally, the increase in the population of Antananarivo between 
2007 and 2009 was estimated at $4 \cdot 8 \%$ on the basis of findings from health and demographic surveys in 2004 and 2008, whereas the annual population growth rate in Madagascar was estimated at 2.8\% (National Institute for Statistics, Madagascar). This explains the differences between the results expressed in absolute numbers and rates, with mostly upward trends in the absolute numbers of deaths in both younger and older groups (Fig. 2).

Our findings show a correlation between excess mortality and circulation of the influenza virus and suggest that the 2009 pandemic influenza $\mathrm{A}(\mathrm{H} 1 \mathrm{~N} 1) \mathrm{v}$ virus may have caused an increase in mortality in Antananarivo. This increase in mortality would not have been detected in investigations of cases of acute respiratory disease in hospitals, as hospital records are generally not well kept in developing countries and most patients do not initially seek assistance from hospitals. Moreover, a large number of the deaths occurred in the community. In Madagascar, as in many developing countries, problems such as malnutrition, poor access to healthcare, crowded living conditions and a shortage of antibiotics to treat secondary bacterial complications, contribute to the burden of influenza. These findings highlight the importance of accurate diagnosis and early treatment for influenza infection.

\section{ACKNOWLEDGEMENTS}

We thank all the GPs and staff from the participating districts. This study was supported by the Institut Pasteur of Madagascar, the French Ministry of Health, the US Centers for Disease Control and Prevention (Cooperative Agreement no.: U51/ IP000327-01) and the US Department of Health and Human Service (Grant no. 6 IDSEP060001-01-01) via the International Network of Pasteur Institutes.

\section{DECLARATION OF INTEREST}

None.

\section{REFERENCES}

1. Pan American Health Organization. Final report of the XVI Meeting on Vaccine Preventable Disease of the Pan American Health Organization. Washington, USA, 2004.

2. Simonsen L. The global impact of influenza on morbidity and mortality. Vaccine 1999; 17 (Suppl. 1): S3-10.
3. Castilla J, et al. Estimating the impact of the 2009 influenza $\mathrm{A}(\mathrm{H} 1 \mathrm{~N} 1)$ pandemic on mortality in the elderly in Navarre, Spain. Eurosurveillance 2010; 15.

4. Perez-Padilla R, et al. Pneumonia and respiratory failure from swine-origin influenza A (H1N1) in Mexico. New England Journal of Medicine 2009; 361: 680-689.

5. Viboud C, Alonso WJ, Simonsen L. Influenza in tropical regions. PLoS Medicine 2006; 3: e89.

6. Yazdanbakhsh M, Kremsner PG. Influenza in Africa. PLoS Medicine 2009; 6: e1000182.

7. Randrianasolo L, et al. Sentinel surveillance system for early outbreak detection in Madagascar. BioMed Central Public Health 2010; 10: 31.

8. R Development Core Team. $R: A$ Language and Environment for Statistical Computing. Vienna, Austria: R Foundation for Statistical Computing, 2010

9. Gail MH. A bibliography and comments on the use of statistical models in epidemiology in the 1980s. Statistics in Medicine 1991; 10: 1819-1885.

10. Rhodes TE, Freitas SA. Advanced Statistical Analysis of Mortality. Boston, USA, 2004.

11. Randrianja S. Madagascar, le coup d'Etat de mars 2009. Paris: Karthala Editions, 2012, 350 pp.

12. WHO-GOARN Investigation Team. Outbreak of influenza, Madagascar, July-August 2002. Eurosurveillance 2002; 7: 172-174.

13. WHO. Influenza outbreak in the district of Bosobolo, Democratic Republic of the Congo, NovemberDecember 2002. Weekly Epidemiological Record 2003; 78: 94-96.

14. Miller M, et al. Mortality and morbidity burden associated with $\mathrm{A} / \mathrm{H} 1 \mathrm{~N} 1 \mathrm{pdm}$ influenza virus. PLoS Currents 2009; 1: RRN1013.

15. Lemaitre M, Carrat F. Comparative age distribution of influenza morbidity and mortality during seasonal influenza epidemics and the $2009 \mathrm{H} 1 \mathrm{~N} 1$ pandemic. BioMed Central Infectious Diseases 2010; 10: 162.

16. Khandaker G, et al. Systematic review of clinical and epidemiological features of the pandemic influenza A (H1N1) 2009. Influenza and Other Respiratory Viruses $2011 ; 5$ : 148-156.

17. Murray CJL, et al. Estimation of potential global pandemic influenza mortality on the basis of vital registry data from the 1918-20 pandemic: a quantitative analysis. Lancet 2006; 368: 2211-2218.

18. Kunisaki KM, Janoff EN. Influenza in immuno suppressed populations: a review of infection frequency, morbidity, mortality, and vaccine responses. Lancet Infectious Diseases 2009; 9: 493-504.

19. Serfling RE. Methods for current statistical analysis of excess pneumonia-influenza deaths. Public Health Report $1963 ; \mathbf{7 8}: 494-506$.

20. Razanajatovo NH, et al. Viral etiology of influenza-like illnesses in Antananarivo, Madagascar, July 2008 to June 2009. PLoS One 2011; 6: e17579.

21. Chan PA, et al. Distinguishing characteristics between pandemic 2009-2010 influenza A (H1N1) and other viruses in patients hospitalized with respiratory illness. PLoS One 2011; 6: e24734. 